\title{
Spinal cord injury: patients who had an accident, walked but became spinal paralysed
}

\author{
M Masini MD, M R B Alencar MD, E G de Castro Neves MD, C F Alves MD \\ The Hospital for Locomotor System Disease - SARAH, Brasilia DF, Brazil.
}

\begin{abstract}
Out of 1410 patients admitted to the spinal cord injury unit (SARAH) for rehabilitation during a 10-year period (1981-90) 10 had a missed spinal trauma lesion and became paralysed after having overcome the initial injuries and being allowed to walk. Patients were admitted to hospital with a history of being able to walk after an accident and subsequently developing a neurological deficit. Seven patients had radiological findings compatible with instability of the spine. Four had a head injury with coma and an undetected spinal fracture at the first evaluation in the emergency room. Other associated factors were: spinal stenosis, prolapsed disc, infection, foreign bodies, procedures for reduction and stabilization of the fractured spine. We emphasize the need for very careful clinical study and investigation for the diagnosis of multiinjured patients, especially when there is a concurrent brain injury.
\end{abstract}

Keywords: multitrauma; spinal paralysis; delayed diagnosis.

\section{Introduction}

In a small number of patients with spinal cord injury (SCI) the neurological deficit may develop later from the spinal injury. We identified a group of patients who were admitted for rehabilitation following an accident, walked after it and subsequently developed a severe spinal neurological deficit. The clinical histories of these patients indicate that after the accident there was a period when the legs had good movement and they were allowed to walk.

\section{Population and method}

A retrospective analysis of 1410 charts of patients admitted for rehabilitation between 1981 and 1990 to the spinal cord injury unit (HAL/SARAH) was carried out. Ten patients had a clinical history of an accident, walked after it and subsequently became paralysed. All had confirmation of this information made by referee doctors. The charts and radiological examinations were analysed retrospectively in an attempt to identify the cause of the late spinal cord injury and its evolution.

\section{Results}

All patients were young males aged between 6 and 30 years. In seven cases the initial injury was due to a traffic accident and in the remaining cases to a fall, a gunshot wound and a knife lesion. The initial lesion was cervical in three cases, thoracic in six cases and lumbar in one case. Patients were graded according to the Frankel scale of neurological deficit at admission for rehabilitation. Six were graded A (paraplegics) and four $\mathrm{C}$ (one paraparetic and three tetraparetics). The interval between the initial accident and the development of the neurological deficit ranged from minutes to 90 days, with eight cases occurring in the first 30 days. one in the second and one in the third month after the trauma to the spine. Referral to our institution for rehabilitation occurred in a mean period of 2.5 months after the appearance of the deficit. The patients were followed up by us for a mean period of 16 months.

Charts and radiological examination reviews showed that seven had spinal instability secondary to fracture or dislocation (cases 1, 2, 4, 5, 7, 9, 10); four had a head injury and coma in the initial emergency care period (cases 4, 5, 9, 10). The other 
four had, respectively, associated spinal stenosis, herniated disc (case 1), and dislocation of a fixation hook at the level of T6 (case 6). The remaining two had, respectively, an epidural haematoma complicated by infection (case 8 ), and a surgical sequella after removal of a knife blade close to the spinal cord (case 3 ).

Three reports are given to provide further information on our patients. Table I details the initial neurological status immediately after the trauma, the cause of the accident, the interval between the accident and the development of neurological deficit, the neurological status at rehabilitation, the radiological findings and a commentary on the cause of late neurological deficits.

\section{Case reports}

\section{Case 5}

A 44 year old male had a car accident 3 months earlier, suffering a head trauma and being in a coma during the following 18 days. After recovering consciousness he started walking, but rapidly developed tetraparesis. Cervical X-ray demonstrated a fracture-dislocation at $\mathrm{C} 6-7$ (Fig 1). He was admitted for rehabilitation in a wheelchair and graded C. An anterior decompression and stabilisation procedure was performed. He was immobilised for 4 months and his neurological deficit improved to D (ambulatory condition).

\section{Case 9}

A 17 year old male had a car accident and remained unconscious for 24 hours. On recovering consciousness, he complained of dysaesthesiae in the lower limbs. The cervical X-ray was considered to be normal. After 6 days in bed he was allowed to walk to the bathroom, but on walking a few steps he became paraplegic. He was admitted 2 months later, paraplegic, with a sensory level corresponding to T6 (A). Radiological examination demonstrated a fracture dislocation at T3-4 (Fig 2). The degree of neurological deficit was unchanged during the follow up period.

\section{Case 10}

A 14 year old male had a car accident, suffering a head injury with loss of consciousness for a few minutes. On recovering, he walked a few steps and developed lower limbs paralysis. He was admitted 1 month later, with a partial neurological deficit in the lower extremities (C). Lumbar X-rays demonstrated a severe L2 and L3 luxation anteriorly to L4 and L5 (Fig 3 ). After rehabilitation, his condition improved to D.

\section{Discussion}

Special care to avoid secondary trauma and a neurological deficit in trauma patients is frequenlty stressed. Surprisingly, the possible consequence of this situation has not been well studied in the literature. Some contributions in the literature expressed the opinion that deterioration of the initial degree of cord injury occurs because of expansion of haemorrhage and/or oedema but none has taken into consideration patients who have suffered trauma with no initial neurological deficit, who were able to walk and who developed a serious neurological deficit some time afterwards. The overall frequency of these cases in our population is $0.7 \%$ ( 10 cases in 1410 total admissions). But even with a low frequency, the severity ( $60 \%$ being paralysed) indicates the need for better diagnosis in multiinjured and head injured patients.

Haiden et al (1975) and Wagner \& Chehrazi (1982) consider that some patients develop their neurological deficit some time after the trauma. In their opinion this period of time, between the initial trauma and the development of neurological deficit, corresponds to the interval between a second trauma to an already unstable spine. Instability of the spine was identified in seven of our cases, and in four there was the association of a head injury and a period of unconsciousness. Our study showed that some other factors such as spinal stenosis, prolapsed disc, infection, foreign body in the canal and hook dislocation may be responsible for some late spinal cord lesions.

The definition of a second injury was clear in our patients. We found that our seven patients with spinal instability had no such diagnosis established; four had an associated head injury with a period of unconsciousness which might have failed to reveal a 
Table I Patient details

\begin{tabular}{|c|c|c|c|c|c|}
\hline $\begin{array}{l}\text { Initial neurological status } \\
\text { immediately after trauma }\end{array}$ & $\begin{array}{l}\text { Cause of spinal } \\
\text { cord injury }\end{array}$ & $\begin{array}{c}\text { Interval to neurological } \\
\text { deficit }\end{array}$ & $\begin{array}{c}\text { Neurological deficit } \\
\text { status }\end{array}$ & Radiological findings & $\begin{array}{l}\text { Presumed cause of } \\
\text { second trauma }\end{array}$ \\
\hline $\begin{array}{l}\text { Case } 1 \mathrm{E} \\
\text { Recumbent before } \\
\text { laminectomy }\end{array}$ & Fall & 15 days & $\begin{array}{c}\text { Paraplegia } \\
\text { A }\end{array}$ & $\begin{array}{l}\text { Fracture/dislocation } \\
\text { spinal stenosis } \\
\text { T10-11 }\end{array}$ & $\begin{array}{l}\text { Instability after } \\
\text { laminectomy }\end{array}$ \\
\hline $\begin{array}{l}\text { Case } 2 \mathrm{E} \\
\text { Walked to hospital for } \\
\text { assistance }\end{array}$ & Traffic accident & $30 \mathrm{~min}$ & $\begin{array}{c}\text { Paraplegia } \\
\text { A }\end{array}$ & $\begin{array}{l}\text { Fracture/dislocation } \\
\text { T10-11 }\end{array}$ & $\begin{array}{l}\text { Instability and } \\
\text { prolapsed disc }\end{array}$ \\
\hline $\begin{array}{l}\text { Case } 3 \text { E } \\
\text { Elected surgery, removal of } \\
\quad \text { knife }\end{array}$ & Knife & 9() days & $\begin{array}{c}\text { Paraplegia } \\
\text { A }\end{array}$ & Blade of knife T8 & $\begin{array}{l}\text { Surgical trauma where } \\
\text { knife removed }\end{array}$ \\
\hline $\begin{array}{l}\text { Case } 4 \mathrm{E} \\
\text { Head injury, coma without } \\
\text { deficit, walked in hospital }\end{array}$ & Traffic accident & 30) days & $\underset{\mathrm{C}}{\text { Tetraparesis }}$ & $\begin{array}{l}\text { Fracture/dislocation } \\
\text { C7-T1 }\end{array}$ & $\begin{array}{l}\text { Instability/head injury } \\
\text { coma/no x-ray of } \\
\text { the spine }\end{array}$ \\
\hline $\begin{array}{l}\text { Case } 5 \text { E } \\
\text { Head injury, coma without } \\
\text { deficit, walked in hospital }\end{array}$ & Traffic accident & 18 days & $\underset{\mathrm{C}}{\text { Tetraparesis }}$ & $\begin{array}{l}\text { Fracture/dislocation } \\
\quad \text { C6 }-7\end{array}$ & $\begin{array}{l}\text { Instability/head injury } \\
\text { coma no x-ray of } \\
\text { the spine }\end{array}$ \\
\hline $\begin{array}{l}\text { Case } 6 \mathrm{E} \\
\text { Surgery at } 17 \text { th day, walked } \\
\text { out of hospital }\end{array}$ & Traffic accident & 60) days & $\begin{array}{c}\text { Paraplegia } \\
\text { A }\end{array}$ & $\begin{array}{l}\text { Fracture/dislocation } \\
\text { T12-L1 }\end{array}$ & $\begin{array}{l}\text { Hook dislocation at } \\
\text { T8 }\end{array}$ \\
\hline $\begin{array}{l}\text { Case } 7 \mathrm{E} \\
\text { Walking/progressive } \\
\text { weakness in legs }\end{array}$ & Traffic accident & 7 days & Tetraparesis & $\begin{array}{l}\text { Fracture/dislocation } \\
\quad \text { C6 }-7\end{array}$ & $\begin{array}{l}\text { Instability/fracture not } \\
\text { visualised }\end{array}$ \\
\hline $\begin{array}{l}\text { Case } 8 \mathrm{E} \\
\text { Fever and deficit }\end{array}$ & Gunshot wound & 23 days & $\begin{array}{c}\text { Paraplegia } \\
\text { A }\end{array}$ & Gunshot wound T4 & Epidural abscess \\
\hline $\begin{array}{l}\text { Case } 9 \mathrm{E} \\
\text { Minor head injury, walked } \\
\text { to bathroom }\end{array}$ & Traffic accident & 6 days & $\begin{array}{c}\text { Paraplegia } \\
\text { A }\end{array}$ & $\begin{array}{l}\text { Fracture/dislocation } \\
\text { T3-4, no x-ray of } \\
\text { the dorsal spine }\end{array}$ & $\begin{array}{l}\text { Instability, head } \\
\text { injury coma }\end{array}$ \\
\hline $\begin{array}{l}\text { Case } 10 \mathrm{E} \\
\text { Head injury, momentary } \\
\text { loss of consciousness, } \\
\text { walked after the accident }\end{array}$ & Traffic accident & A few steps & $\begin{array}{l}\text { Paraparesis } \\
\text { C }\end{array}$ & $\begin{array}{l}\text { Fracture/dislocation } \\
\mathrm{L} 3-4, \text { rescue } \\
\text { inadequate }\end{array}$ & $\begin{array}{l}\text { Instability, head } \\
\text { injury }\end{array}$ \\
\hline
\end{tabular}

$\mathrm{E}=$ Frankel grade $\mathrm{E}$, no neurological deficit. 


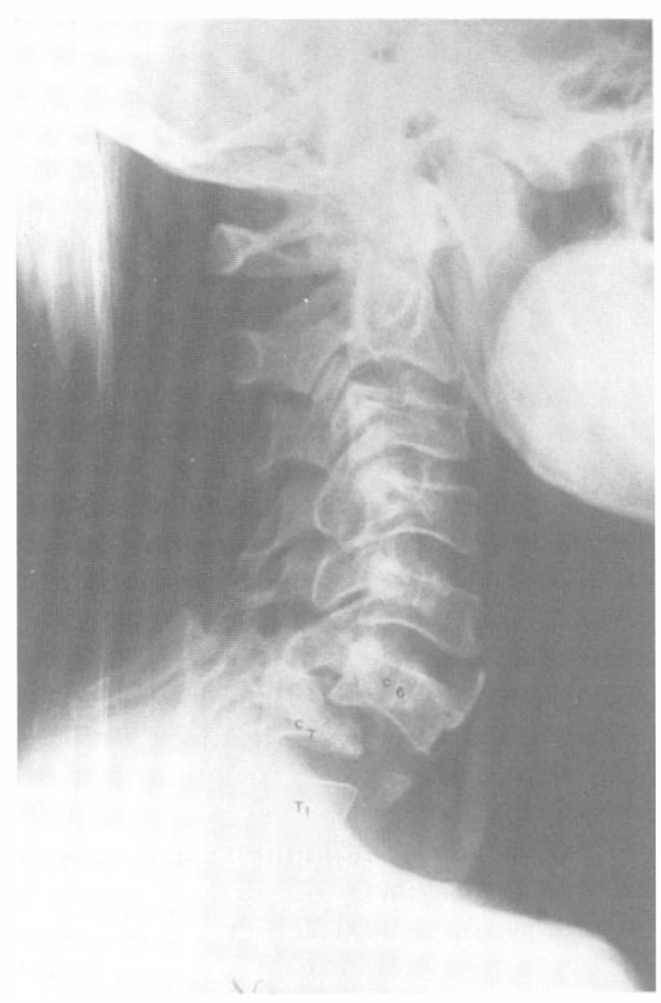

Figure 1 Case 5. Lateral cervical spine X-ray showing $\mathrm{C} 6-7$ fracture-dislocations.

diagnosis of the spinal fracture/dislocation. As they were free to walk, they developed the neurological deficit. One patient was allowed to stand up immediately after the accident. He has a high level unstable fracture at the lumbar spine (case 10) and developed paraparesis after taking a few steps. Case 4 had an $x$-ray of the cervical spine in the emergency room but the examination did not show the $\mathrm{C} 7 / \mathrm{T} 1$ transition and 3 weeks later, when he started walking, he became paraparetic. Concerning the other two cases (cases 5,9), one cervical and one thoracic spine, the x-rays had not been done initially. In a review of the literature, Steudel et al (1988) reported the incidence of head and cervical spine injury as being between 6 and $63 \%$; the severity of brain lesions had a marked influence on the prognosis of the spinal cord injury and the

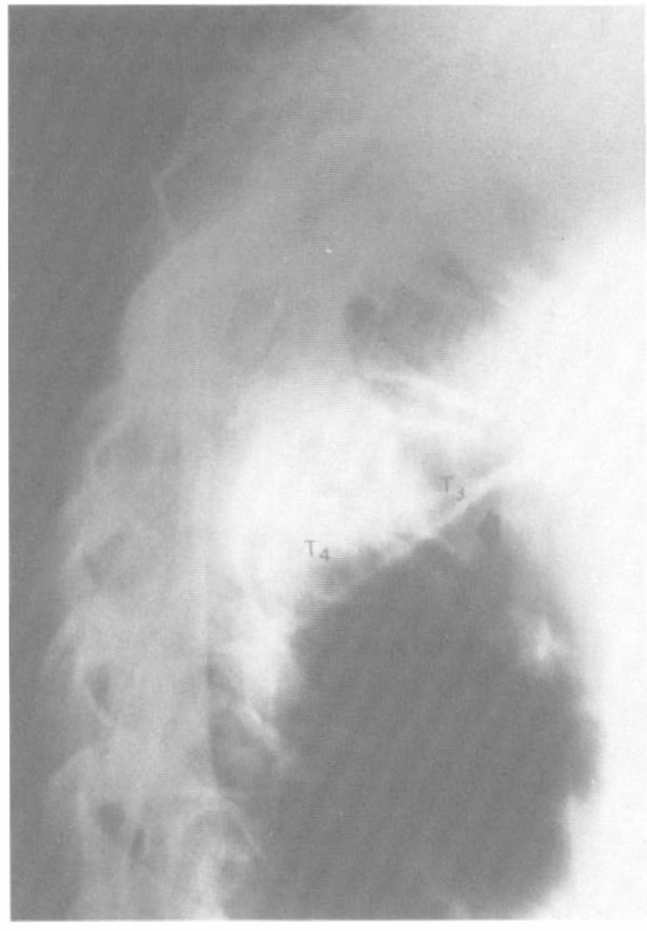

Figure 2 Case 9. Lateral thoracic spine X-ray showing T3-4 fracture-dislocation.

correct identification of cervical lesions was delayed in about $50 \%$ of their patients. In the group with altered consciousness, early spinal stabilization was indicated to prevent further neurological deterioration.

Our study supports the view that all patients with a serious head injury should be treated as if there is a concomitant cervical spine injury until proven otherwise. There are some important associated predisposing factors which include surgery: in case 6 the neurological deficit was related to a surgical procedure and we are not implying that poor management was involved. Rods and hooks can become loose and, in few cases, cause neurological deficit as was referred to by Harrington and Dockson (1973); these risks are associated with all spinal stabilization procedures. The procedure to remove part of a knife is very dangerous and can 


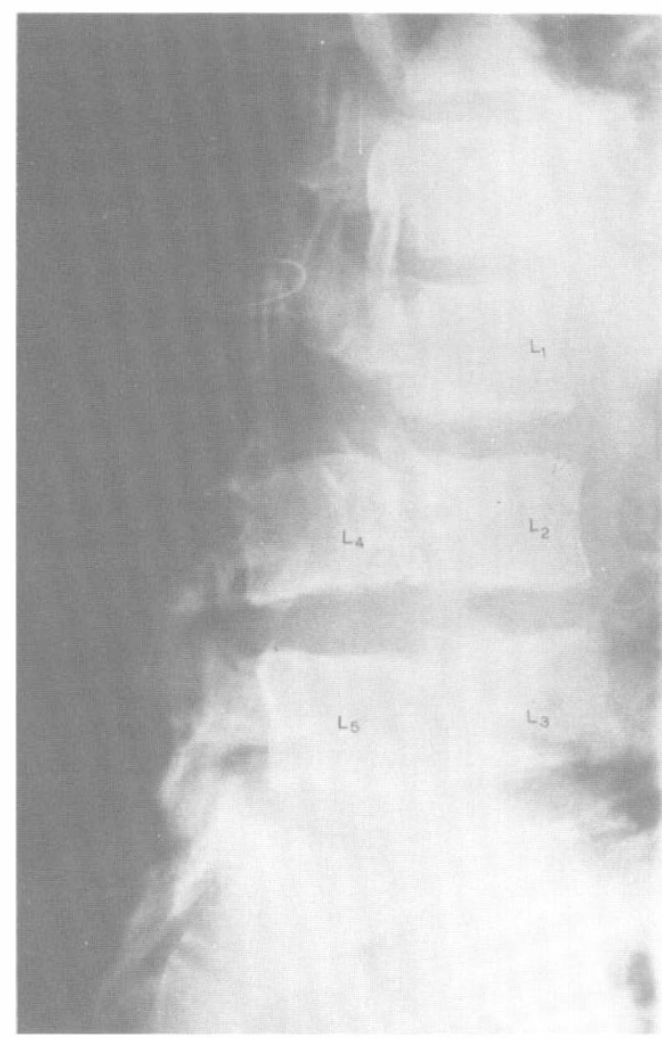

Figure 3 Case 10. Lateral lumbar spine X-ray showing severe L2 and L3 luxation anteriorly to L4 and L5. cause an inadvertent neurological deficit as in case 3 .

Laminectomy is the correct procedure for spinal stenosis as occurred in case 1 , but must be associated with some stabilizing procedure when associated with instability. Infection is a possible evolution of a gunshot wound of the spine (case 8). Attention must be paid to osteomyelitis and discitis. There is often contamination of a haematoma in the wound of the spine in these cases.

Case 2 demonstrates the inadequate rescue of a patient with severe trauma to the spine, which also happened to case 10 . Inadequate examination in the emergency was the most frequent cause of later neurological deficits in patients with spinal trauma in our review, calling attention to the necessity to carry out rehabilitation procedures only after recent and thorough radiological evaluation of the spine.

With this routine, doctors involved in the treatment of the mulitiinjured should appreciate the experiences of doctors in spinal cord injury units, and should protect their patients from having a second injury with a severe neurological deficit and serious consequences for the individual, family and society. In this way they will also protect themselves against being sued for malpractice.

\section{Bibliography}

Frankel HL. Hancock DO. Hyslop G. Melzak U. Michaelis LS. Ungar GH et al (1969) The value of postural reduction in the initial management of closed injuries of the spine with paraplegia and tetraplegia. Paraplegia 7: $179-192$.

Fried IC (1974) Cervical spinal injury during skeltal traction. JAMA 229: 181-183.

Harrington PR. Dockson JH (1973) Development and further prospects of internal fixation of the spine. Ir J Med Sci 9: 773-778.

Haiden JS. Weiss MH. Rosemberg AW (1975) Management of cervical spinal cord trauma in Southern California. I Neurosurg 43: 732-736.

Masini M. Neto NHF. Neves EGC (1990) Experience with a spinal cord unit in Brasilia. Brazil. Paraplegia 28: $17-24$.

Marshall LF. Knowlion S. Garfin SR. Klauber MR. Eisemberghm. Kopaniky D et al (1987) Deterioration following spinal cord injury. J Neurosurg 66: 4(0)-4(0).

Monro E. Laborde J. Bahniuk E. Bohlman HH. Samson B (1980) Comparison of fixation of spinal fractures. Clin Orthop 152: 303-310.

Soderstrom CA. Brumback RI (1986) Early care of the patient with cervical spine injury. Orthop Clin North AM 17: 3-13.

Steudel WI, Rosenthal. Lorenz R. Merdes W (1988) Prognosis and treatment of cervical spinal injuries with associated headtrauma. Acta Neurochir (Wien) 43: S85-90.

Wagner JC. Chehrazi B (1982) The decompression and neurological outcome in acute cervical spinal cord injuries. J Neurosurg 56: 699-7(0)5. 